\title{
ENSINO DE LÍNGUA ESTRANGEIRA NO BRASIL: INTERFACES DA ABORDAGEM DE CONTEÚDO E LINGUAGEM NO ENSINO REMOTO
}

\section{ARTIGO ORIGINAL}

SILVA, Ana Lúcia Farias da ${ }^{1}$

RAMOS, Teresa Cristina Giarolla ${ }^{2}$

SODRÉ, Rachel Fontes ${ }^{3}$

SILVA, Ana Lúcia Farias da. RAMOS, Teresa Cristina Giarolla. SODRÉ, Rachel Fontes. Ensino de Língua Estrangeira no Brasil: Interfaces da abordagem de conteúdo e linguagem no ensino remoto. Revista Científica Multidisciplinar Núcleo do Conhecimento. Ano 05, Ed. 12, Vol. 19, pp. 98-112. Dezembro de 2020. ISSN: 2448-0959, Link de acesso: https://www.nucleodoconhecimento.com.br/educacao/interfaces-daabordagem

\section{RESUMO}

O presente artigo tem como objetivo descrever o desenvolvimento do processo de ensino--aprendizagem de Língua Estrangeira, com o uso da abordagem CLIL (Ensino Integrado de Conteúdo e Linguagem) no ensino do Inglês, no âmbito de um Programa Bilíngue, dentro de um contexto emergencial de Ensino Remoto. Buscamos refletir, também, acerca da adequação das ferramentas tecnológicas no processo de ensino

\footnotetext{
${ }^{1}$ Mestra em Letras pela UFRRJ; Especialista em Língua Portuguesa pela Faculdade São Luis /SP; Graduada e Licenciada em Letras pela UERJ.

2 Mestranda em Educação pela UDE/Uruguai; Especialista em TIC pela UFJF; Graduada e Licenciada em Pedagogia pela Faculdade de Filosofia de Itaperuna/RJ. ${ }^{3}$ Mestra em Comunicação e Cultura pela UFRJ; Graduada em Jornalismo pela UFRJ; Licenciada em Pedagogia pela UNIRIO.
} 
de Língua Estrangeira - especificamente da Língua Inglesa - para uma determinada faixa etária, bem como avaliar a elaboração e a adaptação de materiais, atividades e abordagens pedagógicas à realidade do Ensino Remoto durante o período de isolamento. Para tal reflexão, nossa análise propõe-se a apontar possibilidades e limitações, tanto da abordagem CLIL (Ensino Integrado de Conteúdo e Linguagem), como da modalidade do ensino a distância para a faixa etária observada. Deste modo, além de apresentar o que foi realizado durante a pesquisa, pretendemos refletir sobre possíveis caminhos e contribuir com boas práticas que tornem o processo do Ensino de Língua Inglesa mais significativo e proficiente, dentro da modalidade EaD (Educação a Distância).Defendemos nesta pesquisa a busca por estratégias em um formato digital , por um Ensino de Língua Estrangeira, que se desenvolva de forma mais natural e motivador, bem como a necessidade de políticas públicas voltadas a uma educação pós-pandemia do COVID-19, no sentido da ludicidade e inclusão, visando o desenvolvimento de competências e habilidades do aluno, desde o Ensino Fundamental, transformando a informação em conhecimento.

Palavras-chave: Ensino de Língua estrangeira, Língua estrangeira, Ensino remoto, Abordagem CLIL.

\section{INTRODUÇÃO}

A pandemia de Covid-19 mudou bruscamente, e em escala global, a realização das ações rotineiras. Trabalhar, estudar, consumir cultura, relacionar-se socialmente, obter bens e serviços estão entre algumas das atividades diárias que precisaram ser reinventadas durante o período de isolamento, imposto pelo risco de contaminação.

Diante desse contexto, não será exagero afirmar que a Educação, as Tecnologias da Informação e Comunicação (TICs), nunca foram tão essenciais ao desenvolvimento da cultura, da sociedade e da economia, uma vez que, repentinamente, boa parte das atividades econômicas, sociais e culturais migrou para o ambiente virtual, forçandonos a reconstruir novas formas de desempenhá-las. 
Assim, a pandemia em curso redimensionou, em alto patamar, o fenômeno de globalização, mas num efeito nada esperado: o de ameaça à vida. Posto isso, comunidades de todas as partes do planeta se viram diante de um fatal inimigo comum, identificado como a COVID-19. Nesse cenário, a comunicação e a troca de informações entre as diferentes nações foram fundamentais para o compartilhamento de dados relevantes ao enfrentamento da doença.

Então, nesse panorama, destacou-se o Ensino de Línguas e a importância, não apenas das ferramentas tecnológicas, como também a centralidade e o emergencial uso da Língua Inglesa, que possibilitou a troca de informações de forma ampla, rápida e eficaz, ou seja, acessar dados e informações em uma Língua Estrangeira universal, como o Inglês, se tornou, literalmente, imprescindível.

Segundo Hargreaves (2010), o estudo da Língua Inglesa intensificou-se e foi difundido em diferentes países, já que este idioma é utilizado nas transações comerciais e também nas situações cotidianas, pois além dos nativos falantes, tal idioma se consagrou de forma globalizada. Ademais, os avanços tecnológicos, principalmente a internet, facilitam e proporcionam uma interação intercultural nas relações de comunicação entre os cidadãos e o restante do mundo totalmente globalizado.

Nesta nova e abrupta realidade, o campo da Educação, sobretudo os segmentos do Ensino Infantil e do Ensino Fundamental enfrentaram o desafio de transpor para Ambientes Virtuais de Aprendizagem (AVA), todo seu fazer pedagógico, adaptando rotinas, métodos, abordagens, atividades, linguagem, avaliações e até mesmo os modos de interação professor-aluno e aluno-aluno.

Apesar de desafiador, esse momento mostrou-se propício ao aprendizado, a novas reflexões, possibilitando, com isso, o desenvolvimento de novos saberes adequados às demandas dos novos tempos. Somado a isso, para aprender uma Língua Estrangeira (LE), é necessário desenvolver as habilidades comunicativas e fazer o uso delas. Sendo assim, este artigo propõe relatar de que forma é possível desenvolver as habilidades linguísticas para uma Língua Estrangeira (LE), neste momento de pandemia e ensino remoto, descrever e mobilizar as ferramentas que 
auxiliam o processo de ensino-aprendizagem, além de problematizar as dificuldades encontradas no Ambiente Virtual de Aprendizagem (AVA), através da pesquisa-ação que será apresentada neste estudo, cujo desenvolvimento ocorreu entre março e julho de 2020, no âmbito das aulas de Inglês do Programa Bilíngue, realizado no Ambiente Virtual de Aprendizagem, em uma Escola da rede privada de Ensino Básico, Regular, com alunos do terceiro ano do Ensino Fundamental I.

\section{MATERIAL E MÉTODO}

A elaboração deste artigo está metodologicamente apoiada em uma pesquisa experimental que, segundo Negoceki (2018), caracteriza-se pela submissão do objeto de estudo à influência de certas variáveis, em condições controladas e conhecidas, a fim de que os resultados que as variáveis produzem no objeto sejam observados.

Quanto aos meios, o estudo pode ser classificado como pesquisa-ação, pois "implica um conhecimento prático no qual o próprio pesquisador se envolve nas ações, além de descrever, explicar e prever os fenômenos pesquisados" (BARBIER, 2007, apud NEGOCEKI, 2018). Também Bezerra e Tanajura (2015) entendem a pesquisa-ação como um modelo aberto e dialético de investigação que se situa e organiza-se em torno dos sujeitos de um determinado grupo sobre seu (s) problema (s) cotidiano (s), produzindo saberes e transformando a realidade.

Apoiada nessa visão metodológica acima supracitada, esta pesquisa foi realizada junto a uma turma do Terceiro Ano do Ensino Fundamental em uma Escola de Ensino Regular, da rede privada, que oferece turmas do Ensino Infantil ao Ensino Fundamental. A escola, desde o início de 2019, desenvolve um Programa Bilíngue, com aulas diárias de 45 minutos dentro da abordagem CLIL (Ensino Integrado de Conteúdo e Linguagem), tendo como material de trabalho, o livro didático, dentro desta mesma abordagem e em conformidade com a Base Nacional Comum Curricular (BNCC, 2018). A realização da pesquisa experimental deu-se integralmente em aulas de Ensino Remoto, de Inglês, ministradas diariamente no período de 16 de março a 17 de julho, por meio do Ambiente Virtual de Aprendizagem da escola. 
O desenvolvimento da pesquisa contou com a participação da professorapesquisadora e dos 18 alunos matriculados na turma, identificada como a de número 302, além da coleta de relatos dos responsáveis, da Professora Regente da turma e da Coordenação Pedagógica da escola. Há de se acrescentar, ainda, que todos os alunos da referida turma, envolvidos na pesquisa, são crianças, entre 8 e 9 anos, brasileiras e falantes monolíngues de Língua Portuguesa, como idioma materno.

Ao longo do estudo foram utilizados os seguintes instrumentos para coleta de dados: plano de ensino e planejamentos das aulas ministradas; imagens (fotografias) das atividades realizadas; diários de classe; gravação das aulas e atividades realizadas.

No decorrer da pesquisa foram testadas e analisadas as seguintes variáveis:

a) a oferta de videoaulas, previamente gravadas e a realização de aulas ao vivo por meio de videoconferências;

b) a utilização de três diferentes aplicativos de videoconferência;

c) elaboração e oferta de materiais visuais de apoio diversificados (vídeos, canções, cartazes, mapas, apresentações de slides, materiais concretos, jogos virtuais);

d) oferta das aulas em horários diferentes;

e) implementação de uma rotina e combinados com a turma;

f) interação com membros das famílias dos alunos;

g) coleta dos relatos dos alunos a respeito de suas impressões sobre as aulas e atividades realizadas;

h) coleta dos relatos dos responsáveis a respeito de suas impressões sobre as aulas e atividades realizadas;

i) coleta dos relatos da professora regente da turma e da coordenação pedagógica da escola a respeito de suas impressões sobre as aulas e atividades realizadas; 
j) avaliações formais aplicadas aos alunos.

Os dados coletados foram analisados qualitativamente de acordo com o interesse e envolvimento da turma, considerando-se também o desenvolvimento das habilidades linguísticas observadas (compreensão auditiva, produção oral, leitura e escrita). Diante desse quadro, foram sucedidas avaliações formais das quais nos possibilitaram obter dados quantitativos a respeito do aproveitamento individual de cada aluno. Por fim, nossas observações foram analisadas à luz da revisão de textos pertinentes ao assunto pesquisado.

\section{PROGRAMA BILÍNGUE E ABORDAGEM CLIL}

Posto isto, iniciamos esta seção apresentando o Programa Bilíngue, como vinha sendo desenvolvido antes da pandemia.

Implantado no início do ano letivo de 2019, a proposta do programa tem sido proporcionar aos alunos imersão no idioma Inglês, por meio de aulas diárias de 45 minutos. O desenvolvimento do trabalho conta com aulas e material didático desenvolvidos, segundo a abordagem CLIL (Ensino Integrado de Conteúdo e Linguagem) e com a execução de diversas atividades que visam possibilitar que os alunos vivenciem situações concretas de uso da Língua Estrangeira (LE), tais como: brincadeiras e atividades lúdicas, musicalização, atividades psicomotoras em Inglês, aulas de culinária, aulas de artes, contação de histórias, aulas de ciências no laboratório, aulas de xadrez.

A abordagem CLIL (Ensino Integrado de Conteúdo e Linguagem) tem sido utilizada por Escolas Bilíngues ou que adotam Programas Bilíngues, não apenas no Brasil, como também em diversos países (GUPTA, 2020; NEGOCIKI, 2018; MOLYNEUX ALIANI, 2016; FINARDI, 2016). O acrônimo CLIL (Contentand Language Integrated Learning), que pode ser traduzido por Ensino Integrado de Conteúdo e Linguagem, refere-se a uma abordagem educacional de ensino de conteúdos por meio de uma linguagem adicional, tendo duplo foco - tanto no conteúdo, como na linguagem (GUPTA, 2020; NEGOCIKI, 2018). Tal abordagem possibilita o ensino da língua 
estrangeira implicado em usos reais e contextualizados do idioma, além de permitir trabalhos interdisciplinares. É considerado, também, um meio atraente e eficaz de ensinar o idioma estrangeiro, pois foge ao modelo das tradicionais aulas, focadas em tópicos gramaticais e em listas de vocabulário (FINARDI, 2016).

Além da abordagem CLIL (Ensino Integrado de Conteúdo e Linguagem), a Instituição estudada também vinha apoiando seu fazer pedagógico no uso das TICs (Tecnologias da Informação e Comunicação) e no trabalho de Ensino Híbrido, mesclando atividades presenciais com o uso dos Ambientes Virtuais de Aprendizagem (AVA). Com o início do isolamento, o uso das TICs se intensifica e todo o trabalho pedagógico migra para os Ambientes Virtuais de Aprendizagem, como veremos adiante.

Todavia, precedente ao estudo de caso, acreditamos ser relevante uma breve reflexão acerca dos usos da Tecnologia na Educação e do Ensino Remoto, apoiados em Ambientes Virtuais de Aprendizagem (AVA).

\section{USO DE TECNOLOGIAS NA EDUCAÇÃO}

As evoluções tecnológicas vivenciadas pela humanidade nas últimas décadas vêm transformando gradativamente os modos de viver, conviver, trabalhar e conhecer. Nos últimos anos, o ritmo de utilização das ferramentas e dispositivos tecnológicos se intensificou, propondo novos desafios ao campo da Educação. A partir daí, lidar com a produção e reprodução de conhecimentos, relacionar-se com as novas gerações são fazeres que não podem mais ser pensados de modos tradicionais e estáticos, ao contrário, requerem de nós, educadores, novos e constantes atualizados olhares.

Neste cenário, para que a aprendizagem ocorra, torna-se essencial a interação entre todos os envolvidos com instrumentos facilitadores de comunicação, apropriando-se das tecnologias, ofertando-se vários recursos na mediação pedagógica virtual, contribuindo-se, assim, para uma educação de qualidade e adequada às demandas do contemporâneo. Nessa visão, segundo Mello Ribeiro (2014), é preciso um ambiente de aprendizagem que suplante as escolas restritas, somente pelos textos e 
materiais didáticos, e professores atuantes para suprir necessidades culturais que os outros espaços não são capazes de provocar.

De acordo com Moran; Masetto e Behrens (2000),

[...] irá existir uma grande integração das tecnologias e as metodologias de ensino de aplicações orais, pela escrita e por audiovisual. Os métodos conhecidos não precisam ser abandonados, o que haverá será uma integração destes métodos com as formas utilizadas com as novas tecnologias, permitindo ser usada como facilitadora em uma metodologia de ensino participativo.

Os argumentos postos acima confirmam o quão é necessário aplicar intencionalmente as Tecnologias de Informação e Comunicação (TICs) na Educação, com o intuito de serem estimuladoras, visando-se a assimilação dos conteúdos propostos, sendo atrativas no ato de ensinar, através de profissionais que acompanhem as mudanças. O profissional da Educação deve, portanto, buscar constante aperfeiçoamento, a fim de sair do lugar-comum e utilizar as ferramentas de forma enriquecedora.

Nessa perspectiva, observa-se, portanto, o quanto a utilização de propostas pedagógicas inovadoras, amplamente amparadas pela tecnologia se faz pertinente ao momento em que vivemos, cuja pandemia impulsionou, numa velocidade assustadora, uma nova modalidade de Ensino para este momento, baseada na colaboração e compartilhamento de saberes, encarada como Ensino Remoto.

Ramal (2013) chama a atenção para o fato de que os obstáculos aos professores serão muitos, entre eles a inadequação da formação dos educadores brasileiros, que não contempla as competências com as novas tecnologias. Nessa abordagem, ainda Ramal (2013), considera um perfil diferente para o discente:

[...] sendo comparado como um arquiteto cognitivo, que tenha capacidades de traçar mapas mentais do aluno que vai trabalhar, pois ele seria como um dinamizador da inteligência coletiva com o objetivo de formar comunidades de aprendizado cooperativo.

Sendo assim, essa perspectiva demonstra que a pesquisa que nos convoca, tem muitos aspectos e categorias a considerar para o entendimento desse fenômeno 
educativo, considerando variáveis tecnológicas, metodológicas, cognitivas, entre outras.

\section{ENSINO REMOTO E AMBIENTES VIRTUAIS DE APRENDIZAGEM}

O ambiente virtual deve estar envolvido em um conjunto de saberes, estabelecendose ações que estimulem a construção de conhecimentos, direcionando-se o discente ao êxito. $\mathrm{O}$ importante é respeitar a aprendizagem diferenciada de cada aluno, tendo em vista as limitações e possibilidades individuais.

Mediante a isso, o docente tem um papel imprescindível no ambiente virtual de aprendizagem, pois nesse contexto, não se educa apenas de forma a assimilar o conteúdo trabalhado, mas para que a conexão entre aluno/professor, de forma colaborativa, se estabeleça em todos os momentos da aprendizagem, proporcionando-se, com isso, a qualidade no conteúdo trabalhado.

Nesse âmbito, de acordo com Faria e Lopes (2014), propõe-se uma discussão sobre autonomia, a partir do paradoxo da autonomia/dependência, já que nos Ambientes Virtuais de Aprendizagem (AVAs), é possível e necessário promover a autonomia, libertando o ser humano de tudo que o oprime, que o impede de realizar sua vocação para ser mais, reconhecendo que a história é um tempo e possibilidades. Então, os ambientes virtuais devem ser elaborados de forma a envolver o aluno, buscando-se a curiosidade para a pesquisa, explorando-se os conteúdos numa perspectiva lúdica, a partir de uma tecnologia voltada para a Educação.

Outro ponto fundamental é perceber, segundo estudos já produzidos, que as novas gerações, os chamados nativos digitais, encontram-se numa posição ainda de não ou pouco participantes do processo de ensino aprendizagem com o apoio da tecnologia nas escolas, pois os formadores ainda se encontram como imigrantes digitais nesse ambiente de crescente tecnologia (PRENSKY, 2020).

Nas últimas décadas, a Educação passou por inovações, devido às novas gerações de nativos digitais. Ademais, o uso de ferramentas tecnológicas vem influenciando a 
mediação do conhecimento tradicional e virtual na educação atual. Devido a isso, considera-se, atualmente, nossos alunos como "falantes nativos"- negrito das investigadoras- da linguagem digital de computadores, videogames e internet, o que não indica que saibam refletir e construir aprendizagens significativas pelas suas habilidades tecnológicas. Deste modo, faz-se necessário compreender que a forma de ensinar e aprender precisa ser inovada, transformada para atender de forma ética e moral, as próprias necessidades do ser humano como ser pensante criativo e social, como afirma Santander (2004).

De forma que, como reforça Santos (2016):

A educação deve não apenas formar trabalhadores para as exigências do mercado de trabalho, mas cidadãos críticos capazes de transformar um mercado de exploração em um mercado que valorize uma mercadoria cada vez mais importante: o conhecimento.

\section{ESTUDO DE CASO}

De volta ao estudo de caso aqui proposto, consideramos pertinente registrar que, desde 2018, a Instituição estudada já dispunha de plataforma própria, a qual era utilizada para atividades complementares, dentro da abordagem do Ensino Híbrido. Com o início do período de isolamento, a equipe docente foi desafiada a organizar e adaptar todo trabalho pedagógico para o Ambiente Virtual de Aprendizagem (AVA) da escola. A partir daquele momento, em março de 2020, tem início esta pesquisa-ação, cujo desenrolar e resultados serão expostos a seguir.

Nas primeiras seis semanas do Ensino Remoto, a professora-pesquisadora optou pela gravação de videoaulas, as quais eram diariamente postadas na sala de aula virtual da turma. O tempo de duração dos vídeos variava de 10 a 20 minutos, de acordo com o nível de complexidade do conteúdo. De acordo com a abordagem CLIL, foram ministradas, totalmente em Inglês, aulas das disciplinas Languages (Linguagens/Inglês), Science (Ciências), Social Studies (Estudos Sociais) e Math (Matemática). A fim de facilitar a compreensão dos alunos, a professora-pesquisadora 
lançou mão de diferentes recursos visuais (desenhos na lousa, cartões com imagens, objetos, mapas, material dourado, apresentações de slides e vídeos em Inglês).

Como forma de interagir com os alunos, a professora propôs a participação dos mesmos em fóruns, respondendo questões simples em Inglês e cujo modelo de resposta estruturada já houvesse sido previamente explicado na videoaula correspondente a cada atividade. Outra proposta era a de que os alunos gravassem vídeos curtos de si mesmos (com a ajuda dos responsáveis), apresentando tarefas relativas ao conteúdo trabalhado na videoaula do dia.

Ao longo do período em que tais modelos de aulas e atividades foram mantidos, as pesquisadoras notaram algumas de suas vantagens, sobressaíram, no entanto, suas limitações.

Por um lado, constatou-se que:

a) a postagem das videoaulas permitia a organização das rotinas de estudos dos alunos de acordo com a realidade de cada família, atendendo as diferentes demandas familiares (pais em home office, irmãos em home schooling, compartilhamento de computador pelos membros da família, horários de estudo diferenciados etc.);

b) os vídeos gravados pela professora-pesquisadora sem a participação dos alunos possibilitavam exposições breves e objetivas, posto que não havia interrupções;

c) de modo semelhante, as aulas, sem a participação dos alunos em tempo real, possibilitaram o uso exclusivo do idioma estrangeiro;

d) este modelo de aulas previamente gravadas, também permite a edição, resultando em um produto audiovisual esteticamente mais bem elaborado, sem os imprevistos de uma aula ao vivo.

Em contrapartida, evidenciou-se que: 
a) as aulas ministradas por meio de vídeos não eram compreensíveis a todos os alunos da turma, deixando de alcançar àqueles que apresentaram maior dificuldade para manter a atenção e/ou para compreender o conteúdo;

b) a falta de interação imediata com a professora e com os colegas comprometeu o interesse e o engajamento de boa parte dos alunos, os quais, quando questionados, afirmaram não gostar das videoaulas;

c) os alunos que apresentavam maior facilidade para o aprendizado do idioma, conseguiram realizar as atividades de modo satisfatório, ao contrário dos demais, cujo rendimento e participação foram decaindo ao longo das semanas, conforme análise realizada ao avaliar a frequência à plataforma e o nível de acertos nas atividades enviadas;

d) muitos alunos assistiam aos vídeos, mas não postavam suas atividades, impossibilitando que seu desempenho fosse verificado pela professora-pesquisadora;

e) este modelo de aulas possibilita trabalhar forma expositiva, focando no conteúdo, no ensino lexical e na gramática, porém, não permite que o trabalho com o idioma se volte diretamente para a comunicação.

A esse primeiro momento, seguiu-se uma experiência de duas semanas com o evento de aulas, ao vivo, por videoconferência, e percebeu-se um maior engajamento da turma pela possibilidade de interagir em tempo real com a professora e com os colegas. Observou-se também a possibilidade de acompanhar a realização das atividades pelos alunos e de verificar, durante o tempo de aula, as dificuldades dos alunos, assim como seus avanços, o que passou a nortear os planejamentos das aulas seguintes. Notou-se, também, que este modelo de aula permitiu voltar o foco das aulas para a comunicação em Inglês, tanto entre a professora e os alunos, como entre as próprias crianças.

Se, por um lado, houve muitos ganhos com adoção do recurso da videoconferência, por outro, foi evidenciado, também, algumas limitações. A principal delas diz respeito a questões puramente tecnológicas: há momentos em que a conexão de internet 
(tanto da professora, como dos alunos) falha ou cai, comprometendo o andamento da aula, comprometendo sua qualidade ou, até mesmo, impossibilitando a continuidade da mesma. Outra dificuldade notada foi quanto ao manejo da turma. Por isso, elucidaremos este tópico mais adiante.

Com o término do período experimental de duas semanas, as pesquisadoras entrevistaram os responsáveis a respeito da percepção deles quanto à qualidade das aulas e nível de engajamento das crianças, pedindo que comparassem as duas abordagens: videoaulas e aulas por videoconferência. Como consequência disso, foi constatado que $90 \%$ dos pais apontaram as vantagens das aulas ao vivo, optando por elas, em lugar das aulas gravadas. A mesma pergunta foi feita aos alunos, sendo unânime, a preferência pelas aulas em videoconferências.

Uma vez adotado o modelo de aulas ao vivo, um novo problema se colocou diante de nós: a dificuldade em articular pedagogicamente uma turma de 18 crianças em videoconferência. Nas primeiras aulas estavam muito agitados e eufóricos por rever a professora e os amigos, queriam conversar, contar suas histórias e brincar. Conforme tentávamos impor uma rotina de aula que nos possibilitasse trabalhar, tivemos dificuldades com o excesso de microfones abertos ao mesmo tempo, os ruídos das casas, as constantes interrupções dos alunos. Mesmo quando estavam engajados na aula, atrapalhavam o andamento das atividades, pois faziam perguntas fora de hora e, muitas vezes, mais de um aluno falava ao mesmo tempo.

Em seguida, houve a tentativa de analisar a situação e a buscar soluções que nos permitissem prosseguir com o conteúdo, sem, no entanto, descaracterizar a participação da turma. Fazendo um paralelo entre 0 trabalho realizado presencialmente e a nova realidade, percebeu-se o quanto a transição para o Ensino Remoto foi repentina e abrupta, no meio do bimestre, pois não houve tempo hábil em preparar os alunos para a nova rotina, para o novo modo de interagir e estudar, bem como em acolhê-los no ambiente virtual de forma lúdica e gradativa, ações tipicamente da escola presencial, no início do ano letivo. De modo semelhante, não estabelecemos regras, ensinando-os como se comportar no contexto do Ensino a Distância (EAD). 
A partir de tal constatação, foi elaborado um plano de ação que consistiu em seis slides contendo imagens e comandos curtos em Inglês, com instruções simples sobre como se comportar nas aulas online, assim elaboradas:

1) Respect teacher (Respeite a professora);

2) Respect Friends (Respeite os amigos);

3) Respect timing (Respeite o tempo); ]

4) Turn off your microfone (Desligue seu microfone);

5) Raise your hand to speak (Levante a mão para falar);

6) Have Fun! (Divirta-se!).

A professora-pesquisadora utilizou o apoio visual das imagens para propor aos alunos que adotassem uma nova postura durante as aulas ao vivo, estabelecendo um acordo (Agreement) com a turma. Durante as três semanas que se seguiram, todas as aulas eram iniciadas revendo os Agreements. Com isso, aos poucos, as crianças foram internalizando as regras e mudando seus hábitos, de forma que as ações docentes realizadas pela Regente da turma tornou-se possível e o andamento das aulas passou a acontecer de forma satisfatória.

\section{CONSIDERAÇÕES FINAIS}

O Ensino de Língua Inglesa, na modalidade de Ensino Remoto, com a plena utilização dos Ambientes Virtuais de Aprendizagem (AVAs) tem avançado e pode ser eficiente com o desenvolvimento das habilidades linguísticas associadas a esses recursos tecnológicos e didáticos adequados a cada objetivo no Ensino de Língua Estrangeira. Todavia, o professor deve ter um bom planejamento, refletindo e analisando cuidadosamente a ferramenta mais adequada ao seu objetivo.

Outrossim, postulamos como imprescindível o Ensino da Língua Inglesa, como forma de acesso aos bens culturais universais, ambientes acadêmicos e profissionais do 
mundo globalizado, considerando também uma formação inclusiva que leve o educando a ampliar suas leituras de mundo.

Ademais, as aulas, em tempo real, auxiliam no processo cognitivo em relação ao brincar, dialogar, além de despertarem sensibilidades como as percepções visuais e auditivas, necessárias à aprendizagem. Apesar de certa flexibilização, o uso do inglês contribuiu para acolher os alunos na Língua Materna, o que não prejudicou o aprendizado dos conteúdos propostos, ao contrário, aproximou os alunos da professora-pesquisadora, possibilitando um melhor trabalho no Ensino do idioma. Os resultados foram percebidos nas avaliações formais e no engajamento dos alunos durante as aulas, corroborando o trabalho pedagógico que vai além de ensino dos conteúdos e passa também pela capacidade do educador acolher e se relacionar com seus alunos.

Apesar de um momento pandêmico, extremamente desafiador, principalmente para o Ensino de Língua Estrangeira, sobretudo o Inglês, esta pesquisa enfatizou a necessidade em se acompanhar o avanço das tecnologias digitais e transformar os novos desafios em conhecimentos, para otimizar a capacidade de adaptação dos indivíduos, perante os emergentes contextos educacionais que já se configuraram como uma nova realidade neste momento.

Conclui-se, portanto, que de acordo com o estudo apresentado e pelas leituras vigentes sobre o Ensino de Língua Estrangeira, em interface com métodos e possibilidades múltiplas em Ambientes Virtuais de Aprendizagem, os novos recursos tecnológicos contribuem e estimulam novas perspectivas didático-pedagógicas, nesse panorama de Ensino Remoto, impulsionado pela pandemia. Posto isso, é possível oferecer um ensino de LE, em Programas Bilíngues, em Escolas de Ensino Básico no Brasil hoje, mesmo no Ensino Fundamental, a distância e de qualidade, com prioridade ao desenvolvimento de todas as habilidades linguísticas que um aprendiz deve ativar, para uma aprendizagem de Língua Estrangeira significativa e eficiente. 


\section{REFERÊNCIAS}

BEZERRA, A. da A. C; TANAJURA, Laudelino Luiz Castro. A pesquisa-ação sob a ótica de René Barbier e Michel Thiollent: aproximação e especificidades metodológicas. Revista Eletrônica Pesquisaeduca. Santos, v.07, n.13, p.10-23, jan.jun., 2015. Disponível em:

FINARDI, K. English in Brazil: Insights from the Analysis of Language Policies, Internationalization Programs and the CLIL Approach. EducationandLinguisticsResearch.v.02,n.01,2016.

Disponível:https://www.researchgate.net/profile/Kyria_Finardi/publication/297653683 _English_in_Brazil_Insights_from_the_Analysis_of_Language_Policies_Internationali zation_Programs_and_the_CLIL_Approach/links/5814871508aeffbed6bdf5ba/Englis $\mathrm{h}$-in-Brazil-Insights-from-the-Analysis-of-Language-Policies-InternationalizationPrograms-and-the-CLIL-Approach.pdf. Acesso em: 13/08/2020.

GUPTA, K. C. L. Trabalhos em linguística aplicada. Campinas, v.59, n. 01, Jan./Apr., 2020.Disponível em:

https://www.scielo.br/scielo.php?script=sci_arttext\&pid=S0103$18132020000100042 \&$ lang=pt. Acesso em 13/08/2020.

HARGREAVES, L. H. H. Ensino de inglês a distância, análise de diferentes cursos. Brasília: Clube dos autores, 2011.

MELLO, M. C.; RIBEIRO, A. E. A. Letramento: significados e tendências. Rio de Janeiro: Wak, 2014.

MOLYNEUX, P.; ALIANI, R. Texts, talkand technology: the literacy practices of bilingually-educated students.Trabalhos em Linguística Aplicada. Campinas, n(55.2), mai./ago. 2016. Disponível em: https://www.scielo.br/pdf/tla/v55n2/01031813-tla-55-02-00263.pdf Acesso em 13/08/2020.

MORAN, J. M; MASETTO, M. T; BEHRENS, M A. Novas Tecnologias e Mediação Pedagógica. São Paulo: Papiros, 2000. 
NEGOCEKI, E. B. Uma proposta de ensino baseado na abordagem CLIL: apropriações de uma professora/pesquisadora. Dissertação (Mestrado em Educação) - Centro de Educação, Universidade Federal do Espírito Santo. Vitória, p. 154 ,2018. Disponível:file://C:/Users/User/Downloads/tese_12587_TEXTO\%20FINAL\%20COM PLETO\%20-\%20Edineia\%20print\%20version\%20(1).pdf. Acesso em 13/08/2020.

PRENSKY,M.DigitalNatives,Digitallmmigrants.Disponívelem:<http://www.marcpre nsky.com/writing/Prensky\%20-\%20Digital\%20Natives,\%20Digital\%20Immigrants\%20-\%20Part1. pdf>.Acesso em:.08.2020.

SANTANDER, E. Os desafios da Educação na Sociedade Contemporânea. Revista Paginas Abertas, Ed: Paulus. Ano 29 nํ20, p.37 (2004).

SANTOS, E.; ALVES, L. Práticas Pedagógicas e Tecnologias Digitais, Rio de Janeiro: E-paper, 2016.

WEISZ, T. O diálogo entre o ensino e a aprendizagem. São Paulo: Ática, 2012.

Enviado: Setembro, 2020.

Aprovado: Dezembro, 2020. 